\title{
Recognition of elder abuse by home care workers and older people in Romania
}

\author{
Ioana Caciula, ${ }^{1}$ Gill Livingston, ${ }^{2}$ Rodica Caciula ${ }^{1}$ and Claudia Cooper ${ }^{2}$ \\ 1 "Equilibre" Humanitarian Association, Bucharest, Romania \\ ${ }^{2}$ University College London and Camden and Islington NHS Foundation Trust, London, U.K.
}

ABSTRACT

Background: No previous studies have considered elder abuse in Eastern Europe. We aimed to determine the proportion of home care workers and older people receiving care in a Romanian home care service who correctly identified elder abuse in a vignette, and who had detected elder abuse at work.

Methods: In 2009, care workers and clients of a non-government home care organization serving four areas in Romania completed the Caregiver Scenario Questionnaire to measure ability to identify abuse. We asked the professionals whether they had detected a case of abuse.

Results: $35(100 \%)$ professionals and $79(65.8 \%)$ older people took part. Four (11.4\%) professionals had encountered a case of elder abuse, two $(5.7 \%)$ in the last year. No staff and only one older person correctly identified all four abusive strategies in a vignette. Staff with more professional caregiving experience recognized fewer abusive strategies $(\mathrm{r}=-0.46, \mathrm{p}=0.007)$.

Conclusion: Rates of identification were worryingly low among all professionals, and this was more marked if they had worked longer, suggesting their experiences may have reduced their ability to detect it. Mandatory abuse training for care professionals, and strategies to support reporters of suspected abuse, could help improve the management of elder abuse in all countries.

Key words: elder abuse, home care, knowledge

\section{Introduction}

The United Nations (2002) defines elder abuse as "a single or repeated act or lack of appropriate action occurring within any relationship where there is an expectation of trust, which causes harm or distress to an older person." Abuse is associated with distress and increased mortality in older people and psychological morbidity in carers (Compton et al. 1997). In a recent systematic review, one in four vulnerable elders were found to experience significant abuse (Cooper et al., 2008). Further meta-analysis found that only a third of health care professionals, mainly from the U.S.A., had detected a case in the last year, suggesting that only a small proportion of abuse is currently detected (Cooper et al. 2009). The United Nations has highlighted the importance of a global approach to reducing elder abuse, and cites building greater knowledge as a priority (United Nations, 2002).

Correspondence should be addressed to: Ioana Caciula, "Equilibre" Humanitarian Association, Al. Valea Rosie nr. 4, Bl. M4, Sc. A, Et. 5, Ap. 24, sector 6, Bucharest, Romania. Phone: +40 723545940; Fax: +40 217461052. Email: ioanacaciula@yahoo.com. Received 24 Sep 2009; revision requested 6 Nov 2009; revised version received 16 Nov 2009; accepted 18 Nov 2009. First published online 25 January 2010.
A major criticism of the current elder abuse literature is the paucity of information about what happens outside the U.S.A. and Western Europe. By $2060,30 \%$ of the population in the European Union and $35 \%$ of the Romanian population are projected to be aged 65 or more (Europa, 2009). No-one has, to our knowledge, investigated elder abuse in Eastern Europe. Policies, training and laws about abuse vary greatly between countries, and may lead to different practices among health care professionals in identifying and reporting abuse. In Romania, older people's home care agencies have a duty to: protect clients against abuse and neglect, ensure that staff and clients are informed about procedures for the prevention and identification of possible abuse, support older people to report abuse from staff, and keep a register of abuse allegations and measures implemented to manage them. Home care staff are required to report any suspected abuse to their employers immediately (Ministerul Muncii, 2006). There are no formal requirements to include abuse in the curriculum for adult social care workers in Romania.

The aim of this study was to determine the proportion of home care workers and older people 
recruited from a Romanian home care agency who correctly identify elder abuse in a vignette, and the proportion of care workers who had identified a case of abuse in their practice in the past year. We also explored the predictors of correctly identifying abuse.

\section{Methods}

\section{Setting and participants}

The Equilibre Humanitarian Association (EHA) is a non-government organization operating in Romania, which provides home care services to older people in four areas of the country: Bucharest (sector 6), Drobeta Turnu-Severin, Orsova and Baia de Arama. All are urban areas, with the exception of Baia de Arama which includes urban and rural districts. The services provided include meals preparation, personal care and domestic help, as well as assistance with taking medication.

One of the researchers (IC) approached all home care workers employed by EHA and the older people who were receiving home care services about taking part in the survey between April and August 2009. We excluded older people who were unable to understand the questions and communicate their answers due to cognitive or physical impairments. All the participants gave written, informed consent to be involved in the study, and were assured that their decisions whether or not to participate would not affect their relationship with the agency. Ethics committees in Romania do not review studies that do not involve an experimental treatment, or samples taken for screening or diagnostic purposes. In line with this national policy, therefore, this study was not submitted to an ethics committee.

\section{Procedures}

Participants completed a questionnaire either at home (older people) or at the agency (staff). The questionnaires did not include personal identifiers so that responses were anonymous.

\section{Instruments}

We asked standardized questions about sociodemographic characteristics, including sex, age, ethnic and educational background and the number of years of professional caregiving experience of home care workers. We asked if they had ever detected a case of elder abuse in their work and if they had done so in the past year. Given the high prevalence of abuse in vulnerable adults, we would expect the answer "yes" to this question if abuse was being detected (Cooper et al., 2009). For the older people, we recorded whether they lived alone and we used the Mini-mental State Examination (MMSE) to measure cognitive impairment (Folstein et al., 1975).

All participants completed the Caregiving Scenario Questionnaire (CSQ). The CSQ asks whether different strategies for managing challenging behavior by a person with dementia are abusive (Selwood et al., 2007; Thompson-McCormick et al., 2009). We added one extra strategy to the original questionnaire in order to measure detection of physical abuse. The vignette is about a man who works full-time and cares for his mother who has dementia. Clinical features described include problems with memory, persecutory beliefs that he is stealing from her, night-time agitation, repetitive purposeless behavior, wandering outside the house while he is at work and refusing help with self care and medication. The vignette is followed by a list of 14 management strategies. Respondents rate each strategy on a 6-point Likert scale. Possible responses are good idea and helpful; possibly helpful; not sure; unlikely to help; bad idea but not abusive; and abusive. Four of the strategies are abusive as defined by the definition of elder abuse used by the World Health Organization Center for Interdisciplinary Gerontology, and judged by an expert panel (Selwood et al., 2007). Five were judged to be possibly abusive. For example, hiding tablets in food or drink may be abusive if the person had capacity to judge whether they wanted to take them, but would not be abusive if they did not have this capacity and any local protocols were followed. Five items are not abusive according to standard definitions of abuse. Table 1 lists all the strategies and, for those judged to be definitely or possibly abusive, gives the type of abuse.

\section{Analysis}

We analyzed the data using SPSS version 14.0, and used two-tailed tests for all analyses and appropriate summary statistics to describe the sample. We compared the proportions in each group who reported that each of the strategies was abusive. Univariate tests were used to explore putative associates of the number of abusive strategies correctly identified by the older people and professionals. Our three continuous variables all approached the normal distribution, defined as having a skewness statistic between -1 and 1 . The skewness statistics were: MMSE score (-0.88), age of older person $(-0.56)$, number of years of experience (staff) (0.88), and the number of abusive strategies correctly identified $(0.023$ for the older person sample and 0.13 for the home care worker sample). 


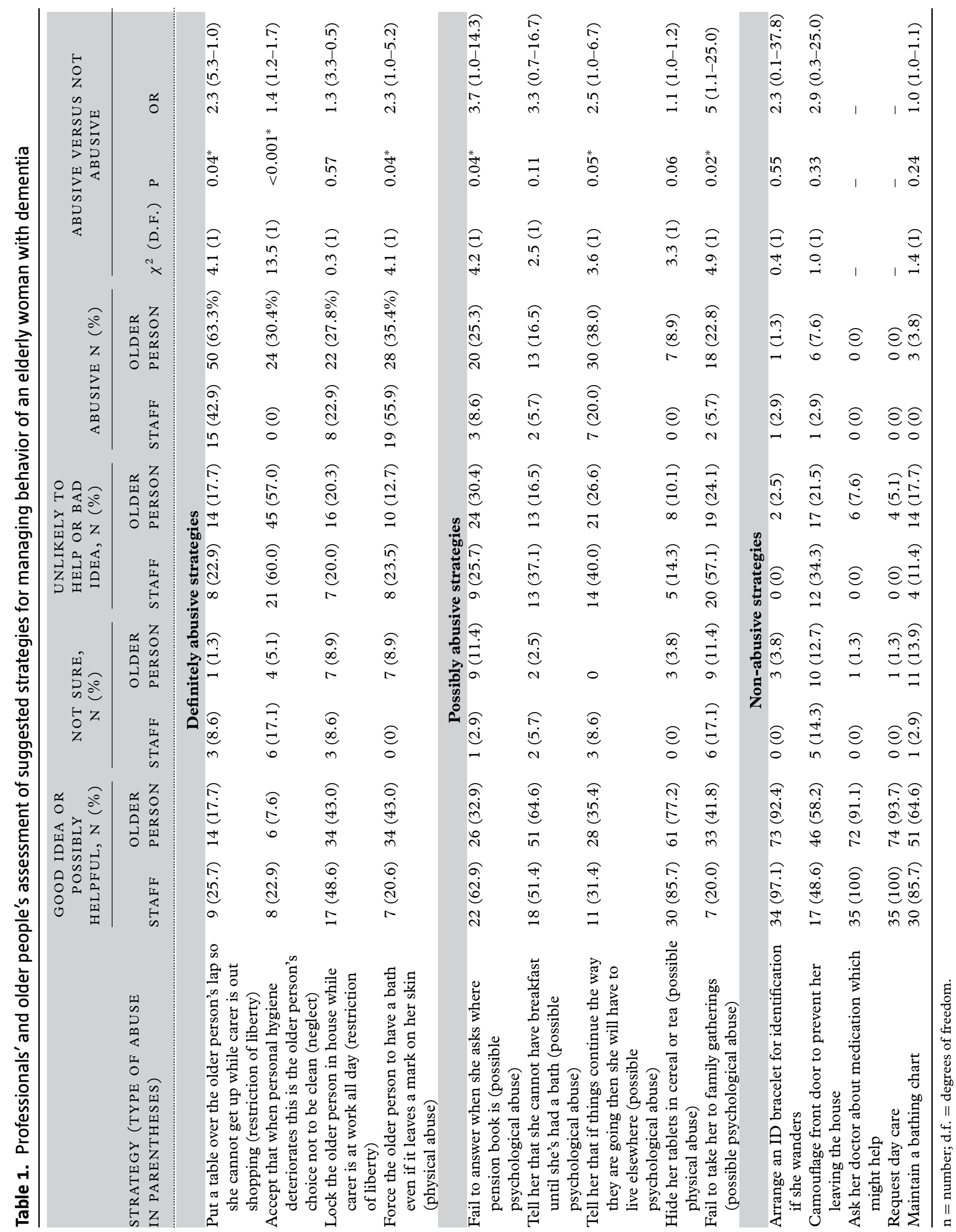


We also compared the number of definitely abusive strategies correctly identified by the older people and professionals. Linear regressions were conducted in the older people and home care worker populations, with the number of abuse strategies correctly identified being the dependent variable, and all the characteristics studied being the independent variables, except those categories which included less than three people (identifying abuse in the past year, carer gender and ethnicity).

\section{Results}

All $35(100 \%)$ home care workers approached participated in the study. Two of the staff were qualified nurses, the rest were home care workers who had completed the three-month training program required by the agency. We interviewed $79 / 120(65.8 \%)$ of the older people receiving home care services. Severe physical or cognitive impairment, living in a rural, inaccessible location and refusing to take part were the main reasons for non-participation.

The sociodemographic characteristics of the sample are shown in Table 2. The ages of the older people ranged from 52 to 97 years, and their MMSE scores from 10 to 30 . Four $(11.4 \%)$ of the staff reported ever encountering a case of elder abuse, and in two $(5.7 \%)$ cases this was in the last year.

Table 1 displays the responses to the Caregiver Scenario Questionnaire, and the univariate comparisons for the proportion who identified each strategy as abusive. Older people were more likely than staff to identify neglect correctly and restriction of liberty as abusive. They were also more likely to define three of the possibly psychologically abusive strategies as abuse. The older people also tended to be more likely to identify medicating the dementia patient by hiding tablets in food or drink as abusive, while none of the staff judged this to be abuse. Home care workers were more likely than older people to correctly identify the physical abuse item. Few of the participants incorrectly identified nonabusive strategies as abusive, and there were no

Table 2. Descriptive statistics for the sample and their relationship to the total number of abusive strategies identified

\begin{tabular}{|c|c|c|c|c|c|}
\hline CHARACTERISTIC & & $\begin{array}{l}\text { N (\%) OR MEAN } \\
(\mathrm{SD} ; \mathrm{RANGE})\end{array}$ & $\begin{array}{l}\text { NUMBER OF } \\
\text { ABUSIVE } \\
\text { STRATEGIES } \\
\text { CORRECTLY } \\
\text { IDENTIFIED }\end{array}$ & $\begin{array}{l}\text { TEST } \\
\text { STATISTIC }\end{array}$ & $\mathrm{P}$ \\
\hline \multicolumn{6}{|c|}{ Older people } \\
\hline Gender & $\begin{array}{l}\text { Male } \\
\text { Female }\end{array}$ & $\begin{array}{l}17(21.5 \%) \\
62(78.5 \%)\end{array}$ & $\begin{array}{l}1.47(0.87) \\
1.60(1.08)\end{array}$ & $\mathrm{t}=0.44$ & 0.66 \\
\hline Age & & $77.9(8.3 ; 52-97)$ & & $\mathrm{r}=-0.002$ & 0.99 \\
\hline Ethnicity & $\begin{array}{l}\text { Romanian } \\
\text { Other }\end{array}$ & $\begin{array}{r}70(88.6 \%) \\
9(11.4 \%)\end{array}$ & $\begin{array}{l}1.50(1.05) \\
2.11(0.79)\end{array}$ & $t=1.69$ & 0.10 \\
\hline Living arrangements & $\begin{array}{l}\text { Lives alone } \\
\text { Lives with others }\end{array}$ & $\begin{array}{l}54(68.4 \%) \\
25(31.6 \%)\end{array}$ & $\begin{array}{l}1.53(0.99) \\
1.64(1.16)\end{array}$ & $\mathrm{t}=0.41$ & 0.68 \\
\hline Education level & $\begin{array}{l}\text { Other } \\
\text { High school or above }\end{array}$ & $\begin{array}{l}41(51.9 \%) \\
38(48.1 \%)\end{array}$ & $\begin{array}{l}1.59(1.02) \\
1.55(1.06)\end{array}$ & $\mathrm{t}=0.14$ & 0.89 \\
\hline MMSE score & & $24.1(3.7 ; 10-30)$ & & $\mathrm{r}=0.037$ & 0.74 \\
\hline & & Professionals & & & \\
\hline Gender & $\begin{array}{l}\text { Male } \\
\text { Female }\end{array}$ & $\begin{array}{c}1(2.9 \%) \\
34(97.1 \%)\end{array}$ & $\begin{array}{l}- \\
-\end{array}$ & - & - \\
\hline Age group & $\begin{array}{l}18-34 \text { years } \\
35-44 \text { years } \\
45-54 \text { years } \\
55-64 \text { years }\end{array}$ & $\begin{array}{r}8(22.9 \%) \\
9(25.7 \%) \\
10(28.6 \%) \\
7(22.9 \%)\end{array}$ & $\begin{array}{l}1.50(0.76) \\
1.33(1.00) \\
1.00(0.94) \\
1.14(0.70)\end{array}$ & $\mathrm{F}=0.55$ & 0.65 \\
\hline Ethnicity & Romanian & $35(100 \%)$ & - & - & - \\
\hline Years of experience & & $4.51(4.04 ; 1-13)$ & - & $\mathrm{r}=-0.46$ & 0.007 \\
\hline Ever identified abuse & $\begin{array}{l}\text { Yes } \\
\text { No }\end{array}$ & $\begin{array}{r}4(11.4 \%) \\
31(88.6 \%)\end{array}$ & $\begin{array}{l}1.50(1.30) \\
1.20(0.80)\end{array}$ & $t=0.66$ & 0.51 \\
\hline Qualifications & $\begin{array}{l}\text { Other } \\
\text { High school }+\end{array}$ & $\begin{array}{l}20(57.1 \%) \\
15(42.9 \%)\end{array}$ & $\begin{array}{l}1.32(0.82) \\
1.13(0.92)\end{array}$ & $\mathrm{t}=0.61$ & 0.55 \\
\hline
\end{tabular}


differences between the groups in the likelihood of doing so.

Older people tended to identify more of the abusive strategies correctly compared with staff (mean number of strategies identified 1.57 (standard deviation (SD) 1.03) vs 1.24 (0.85), $\mathrm{t}=1.66, \mathrm{p}=0.10)$. Fourteen $(17.7 \%)$ of the older people did not identify any abusive strategy correctly, 23 (29.1\%) identified one, $26(32.9 \%)$ two, $15(19.0 \%)$ three, and $1(1.3 \%)$ identified all four strategies correctly. Seven $(20.6 \%)$ of the home care workers did not identify any abusive strategy correctly, $14(41.2 \%)$ identified one, $11(32.4 \%)$ two, $2(5.9 \%)$ three and none identified all four strategies correctly.

Using univariate analysis, the only characteristic studied that was associated with identifying more abusive strategies correctly was the home care worker having fewer years of experience as a caregiver (Table 2). In our linear regressions, with the number of abusive strategies correctly identified as the dependent variable, only having fewer years of experience predicted the staff identifying more strategies correctly $(\beta=-0.46, \mathrm{t}=2.9, \mathrm{p}=$ 0.007 ), and there were no significant predictors of the number of abusive strategies correctly identified among the older people interviewed.

\section{Discussion}

No previous study has examined detection of elder abuse in Eastern Europe, or among community workers in a non-Western country (Cooper et al., 2009). Only $6 \%$ of the home care workers interviewed had knowingly encountered a case of abuse in the past year. This is lower than the prevalence found in a recent meta-analysis, in which a third of health care professionals had detected a case of older adult abuse in the past year (Cooper et al., 2009).

We also found that most of the home care workers were unable to correctly identify abuse in our vignette. They were less likely than the older people to correctly identify neglect, restriction of liberty and possibly psychologically abusive strategies as abuse. They were more likely than older people to identify physical abuse. This may be partially because the staff induction training programs currently focus on medical care and the importance of avoiding physical injury, while the topic of elder abuse is not covered.

The home care workers in this study were half as likely to identify the restriction of liberty and neglect items correctly as abuse, compared to similar English and Australian surveys that asked professionals the same questions (Selwood et al., 2007; Hempton et al., 2009). This may be because the English and Australian workers had specialist mental health professional training, while professionals in the current study did not. Alternatively, it may reflect the higher profile of elder abuse prevention in England (Department of Health and Home Office, 2000; House of Commons Health Committee, 2004). The Mental Capacity Act recently introduced a specific criminal offence of abuse of vulnerable adults to the English and Welsh statute book (Department of Health, 2005). The common induction standards for English social care workers specifically include recognizing the signs and symptoms of neglect and abuse and knowing how to report it (Skills for Care, 2005). By contrast, the Romanian national occupational standards for home care workers do not include training in abuse. Our findings therefore suggest that mandatory training in abuse may be effective. A culture in which there is an expectation that government agencies will act on abuse reports is probably also important.

We considered whether there are cross-national differences in awareness and attitudes towards abuse. However, the older people in our survey were no less likely than the family carers in the previous English survey to correctly identify abuse (Selwood et al., 2007). While populations of family carers and older people are not directly comparable, this would suggest that our findings are not explained by a difference in views between countries about what constitutes abuse.

It is interesting that home care workers with more years of professional experience detected less abuse. This is unlikely to be due to burnout as the prevalence of burnout is inversely related to time working as a professional carer (Zimmerman et al., 2005; Edvardsson et al., 2009). It is possible that over time home care workers either changed their views about what management strategies were acceptable to fit in with their experiences, or left the profession. The training received by those who joined the profession more recently may have better equipped them to identify abuse. The home care profession was recently nationally recognized and new professional standards were introduced in 2004 and for accreditation of training agencies (Consiliul National de Formare Profesionala a Adultilor, 2000). Around half of the home care workers had five or more years of experience in the profession so would have undergone training prior to the implementation of these standards.

\section{Limitations}

Interviews were conducted by a member of the EHA staff, but as questionnaires were anonymous 
we do not think this is likely to have affected the answers given. The study took place within one home care agency and the sample size was limited, so we cannot generalize from these findings to all home care workers or older people living in Romania. While our expert panel used standard WHO criteria, which reflect Romanian guidelines to judge whether or not the strategies were abusive, views about what constitutes abuse vary between countries. For example, we have categorized the item accept that it is her choice not to be clean as abusive. This is because it is thought that if a person does not have capacity to understand the implications for their health, wellbeing and social interactions of deciding not to be clean, then there is a duty to act in their best interests, and not to do so is neglectful. However, a recent Australian study using the CSQ categorized this item as nonabusive, in line with the Victorian state guidelines that it is the older person's choice as to whether they are clean or not (Hempton et al., 2010).

\section{Conclusion}

This is the first survey to explore the identification of elder abuse in Eastern Europe. Rates of identification were low among the home care workers, and only $6 \%$ had detected a case of abuse in the past year. Workers with more experience were worse at identifying abuse, suggesting that experience moderated their views about what was abuse. We recommend mandatory abuse training for health care professionals. Strategies to support staff who report suspected abuse in all countries would be an important step towards improving the management of elder abuse.

\section{Conflict of interest declaration}

IC works for, and RC manages, the home care agency where the study took place.

\section{Description of authors' roles}

IC, CC and GL designed the study and analyzed the data; IC and CC prepared the first draft; all authors revised the content critically for important intellectual content and approved the final version.

\section{Acknowledgments}

We thank the carers and patients who took part in the study.

\section{References}

Compton, S. A., Flanagan, P. and Gregg, W. (1997). Elder abuse in people with dementia in Northern Ireland: prevalence and predictors in cases referred to a psychiatry of old age service. International fournal of Geriatric Psychiatry, 12, 632-635.

Consiliul National de Formare Profesionala a Adultilor (2000). Standarde Ocupationale - Ingrijitor Batrani la Domiciliu. Bucharest: CNFPA.

Cooper, C., Selwood, A. and Livingston, G. (2008). The prevalence of elder abuse and neglect: a systematic review. Age and Ageing, 37, 151-160.

Cooper, C., Selwood, A. and Livingston, G. (2009). Knowledge, detection and reporting of abuse by health and social care professionals: a systematic review. American Fournal of Geriatric Psychiatry, 17, 826-838.

Department of Health and Home Office (2000). No Secrets: Guidance on Developing and Implementing Multi-agency Policies and Procedures to Protect Vulnerable Adults from Abuse. London: The Stationery Office.

Department of Health (2005). The Mental Capacity Act. London: The Stationery Office.

Edvardsson, D., Sandman, P., Nay, R. and Karlsson, S. (2009). Predictors of job strain in residential dementia care nursing staff. Fournal of Nursing Management, 17, 5965.

Europa (2009). Population Projections 2008-2060. http://europa.eu/rapid/pressReleasesAction.do?reference= STAT/08/119; last accessed 11 November 2009.

Folstein, M. F., Folstein, S. E. and McHugh, P. R. (1975). "Mini-mental state": a practical method for grading the cognitive state of patients for the clinician. Fournal of Psychiatric Research, 12, 189-198.

Hempton, C. et al. (2010). Perceptions of elder abuse in Australia. Unpublished work, Department of Psychiatry, University of Melbourne.

House of Commons Health Committee (2004). Elder Abuse. London: The Stationery Office.

Ministerul Muncii SSSF (2006). Privind aprobarea Standardelor minime specifice de calitate pentru serviciile de ingrïire la domiciliu pentru persoanele vârstnice si pentru centrele rezidentiale pentru persoanelevârstnice. Bucharest: Monitorul Oficial.

Selwood, A., Cooper, C. and Livingston, G. (2007). What is elder abuse - who decides? International fournal of Geriatric Psychiatry, 22, 1009-1012.

Skills for Care (2005). Common Induction Standards: Social Care (Adults). London: The Stationery Office.

Thompson-McCormick, J., Jones, L., Cooper, C. and Livingston, G. (2009). Medical students' recognition of elder abuse. International fournal of Geriatric Psychiatry, 24, 770-777.

United Nations (2002). Abuse of Older Persons: Recognizing and Responding to Abuse of Older Persons in a Global Context. New York: United Nations.

Zimmerman, S. et al. (2005). Attitudes, stress, and satisfaction of staff who care for residents with dementia. Gerontologist, 45, 96-105. 